\title{
El problema bibliográfico de las comedias sueltas sin datos de impresión: apuntes para la identificación de algunas ediciones financiadas por la librera Teresa de Guzmán? \\ The Bibliographical Problem of the Theatre Chapbooks without Printing Information: Notes for the Identification of some Editions Financed by Bookseller Teresa de Guzmán
}

\section{Alejandra Ulla Lorenzo}

Universidad Internacional de La Rioja

alejandra.ulla@unir.net

ESPAÑA

[Hipogrifo, (issn: 2328-1308), 8.1, 2020, pp. 579-600]

Recibido: 26-08-2019 / Aceptado: 27-09-2019

DOI: http://dx.doi.org/10.13035/H.2020.08.01.39

Resumen. Uno de los principales problemas bibliográficos que presenta el teatro del Siglo de Oro impreso se relaciona con la correcta identificación y adscripción tipográfica de las ediciones en formato suelto que muestran datos de impresión falsos o no presentan ningún tipo de información a este respecto. La comedia suelta fue la forma más común para la publicación del teatro áureo, pero también la

1. Este trabajo se inscribe en el proyecto Impresos sueltos del teatro antiguo español: base de datos integrada del teatro clásico español (ref. PID2019-104045GA-C55), financiado por el Ministerio de Ciencia, Innovación y Universidades y fondos FEDER. Quisiera dedicar este trabajo a la profesora Meg Greer, quien ha sabido enseñarme siempre con la humildad y generosidad propias de las verdaderas maestras. 
más rentable para impresores y libreros. Estas comedias se imprimieron de manera individual en formato cuarto y se publicaron desde el siglo XVI y hasta el XIX, aunque el período de mayor florecimiento coincide con los siglos XVII y XVIII.

Tras ofrecer un estado de la cuestión que contribuirá a revisar el concepto de suelta así como a situar su principal problema bibliográfico, el objetivo del presente artículo consistirá en plantear una aproximación a un análisis tipográfico y ornamental que nos ayude a identificar los datos de impresión del conjunto de sueltas teatrales que, entre 1733 y 1737, fueron financiadas y vendidas por Teresa de Guzmán, gerente de la lonja de comedias situada en la Puerta del Sol en Madrid.

Palabras clave. Teatro del Siglo de Oro; impresos teatrales sueltos; tipografía, ornamentación; Teresa de Guzmán.

Abstract. One of the main problems that present the Golden Age theatre printed editions is the identification and typographical ascription of the chapbooks which have false printing information or do not present any kind of information to this respect. The theatre chapbook was the most common publishing format for the Golden Age theatrical texts and also the most profitable for printers and booksellers. These collected plays printed individually in fourth were published already from the 16th century until 1850, although the period of his more extensive production comprises the $17^{\text {th }}$ and $18^{\text {th }}$ centuries.

After offering a state of affairs that will contribute to revising the concept of suelta as well as situating its main bibliographical problem, the aim of the present piece will be to propose a typographical and ornamental analysis that help us to identify the printing information from the group of theatre chapbooks that, between 1733 and 1737, were financed and sold the bookseller Teresa de Guzmán, manager from the plays market located at the Puerta del Sol in Madrid.

Keywords. Golden Age theatre; Theatre chapbooks; Typography; Ornamentation; Teresa de Guzmán.

\section{INTRODUCCIÓN}

Uno de los principales problemas bibliográficos que presenta el teatro del Siglo de Oro impreso se relaciona con la correcta identificación y adscripción tipográfica de las ediciones antiguas que muestran datos de impresión falsos o no presentan ningún tipo de información a este respecto. Si bien es cierto que dichas dificultades afectan a los dos formatos de publicación propios del género dramático - partes de comedias y sueltas-, las cifras nos indican que las incógnitas de atribución a un taller de imprenta se multiplican en el segundo caso. Un buen ejemplo, a este respecto, es el conjunto de sueltas teatrales cuya impresión financió la librera Teresa de Guzmán, gerente de la Lonja de Comedias de la Puerta del Sol, entre 1733 y 1737. Estas presentan características tipográficas diferentes que sugieren su atri- 
bución a distintos talleres; aunque la ausencia de datos de publicación en la mayor parte de los casos no nos permita saber a cuáles.

El objetivo del presente artículo consiste en la propuesta de un análisis de los elementos estructurales de este grupo de ediciones que nos lleve a identificar algunas de las oficinas de las cuales salió una parte del conjunto de sueltas que Teresa de Guzmán vendió en su librería madrileña. El examen seguirá los presupuestos de la crítica tradicional pero en él se plantearán, asimismo, las ventajas que nos podrían ofrecer las herramientas tecnológicas. La investigación que exponemos estará precedida por un estado de la cuestión que contribuirá a revisar el concepto de suelta así como a situar su principal problema bibliográfico. Este podría encontrar solución a través de un repertorio de conjunto que identificara y controlara bibliográficamente estos materiales sueltos. Por tal motivo, este trabajo finaliza con unas conclusiones en las que se reflexiona a este respecto.

\section{LA COMEDIA SUELTA Y SUS CARACTERÍSTICAS (SIGLOS XVI-XIX)}

Las sueltas teatrales recogen, en formato cuarto, la edición de una comedia, habitualmente del Siglo de $\mathrm{Oro}^{2}$. Esta modalidad editorial comenzó a publicarse en el siglo XVI y proliferó, con numerosos cambios, hasta bien avanzado el siglo XIX. Las primeras obras teatrales que se imprimen sueltas pertenecen al período 15011520, presentan un formato en cuarto y algunas de ellas pequeñas figuras xilográficas. Este modelo perdura hasta los primeros años del siglo XVII, particularmente en Valencia, tal y como nos demuestran los volúmenes Doce comedias famosas de cuatro poetas valencianos (1609) y Norte de la poesía española (1616). Posteriormente, los impresores buscaron otras formas más baratas y rentables para imprimir sueltas, por lo que abandonaron las ilustraciones xilográficas y empezaron a utilizar tipos menores para los títulos y repartos ${ }^{3}$. Cuando se introdujo la prohibición de imprimir comedias en Castilla en $1625^{4}$, continuaron publicándose, particularmente en Sevilla, aunque lo hicieron sin datos de imprenta ${ }^{5}$. Las sueltas de este período se imprimieron muchas veces en cuarto conjugado, un formato que pasó a convertirse en cuarto sencillo hacia 1630. En esta fecha se producen, asimismo, otros cambios que pueden ayudarnos, muchas veces, a fechar una suelta sin datos. A finales de esta centuria y durante toda la siguiente, por ejemplo, fueron apareciendo en sus portadas los números de serie, que se hicieron habituales durante el siglo XVIII'. La producción de sueltas aumentó notablemente en el siglo XVIII debido a la lectura y a las representaciones privadas. Durante toda esta centuria este tipo de edición se publicó en las principales ciudades de la Península Ibérica y América y, de hecho, constituyó un fragmento importante del número total de im-

2. Bainton, 1988, p. 55

3. Cruickshank, 2002, pp. 278-280.

4. Recuérdese que esta se alargó hasta 1634 tal y como ha explicado Moll, 1974.

5. Cruickshank, 1981, pp. 11-12.

6. En este tipo de formato cada cuaderno está integrado por dos pliegos doblados dos veces que forman ocho hojas

7. Vega García-Luengos, 2009, p. 38. 
presos de ficción que salieron de estos talleres ${ }^{8}$. El formato editorial de la comedia suelta perduró hasta los años 30 del siglo XIX, aunque lo hizo con un éxito menor. Es posible hacer referencia a sueltas tempranas -las impresas antes de 1700-y tardías - las publicadas después de esta fecha ${ }^{9}-$. También podemos situar el corte cronológico en torno a 1670, como ha señalado Gómez Sánchez-Ferrer ${ }^{10}$, por cuanto las anteriores a este año presentan todavía vacilaciones estructurales que, sin embargo, desaparecen a partir de la década de los setenta del siglo XVII ${ }^{11}$.

En lo que se refiere a los tipos de letra empleados en este formato editorial debe señalarse que el más generalizado parece haber sido la lectura o cícero y, concretamente, en un tamaño de 79-89 milímetros por 20 líneas $^{12}$. Tamaños mayores (8589 milímetros) fueron usados sobre todo por los fundidores de tipos de Madrid en la segunda mitad del siglo XVII. Los sevillanos -y, probablemente, también impresores de otros puntos de la Península- utilizaron en el siglo XVII tipos de menos de 70 milímetros por 20 líneas. Aquellos tamaños que comprenden entre los 70 y los 79 milímetros (lectura chica o filosofía) parecen remitirnos al siglo XVIII'3. Cruickshank ha señalado los usos de la tipografía cursiva en los siglos XVI y XVII a través de la propuesta de un impagable atlas ${ }^{14}$; asimismo ha incidido en la importancia de la identificación de este tipo de letra puesto que, frente a la homogeneización de la redonda, permite agrupar los distintos talleres ${ }^{15}$. Por otra parte, debe tenerse en cuenta la ornamentación que presentan las comedias sueltas, pues su análisis revela un sistema iconográfico integrado, fundamentalmente, por capitales ornadas, marcas de impresores y ornamentos tipográficos de tipo estructural. En general, son muy pocos, por tanto, los ejemplos en los que se localizan imágenes vinculadas con el contenido del texto y que lo ilustran. Este grupo se nutre generalmente de grabados relacionados con los personajes tipo de la comedia áurea que no estaban creados ad hoc para cada edición, sino que la imprenta correspondiente disponía de un conjunto de tacos de figuritas que podían utilizarse y reutilizarse en distintas ocasiones puesto que se ajustaban a textos diferentes ${ }^{16}$. Son los que observamos en los volúmenes Doce comedias famosas de cuatro poetas valencianos (1609) y Norte de la poesía española (1616). Sin embargo, se trata de una herencia que tiene su final con las ediciones de los autores valencianos, puesto que no volvemos a encontrar ejemplos de ediciones teatrales con ilustraciones hasta el siglo XVIII.

Las sueltas se publicaban y vendían de forma individual. No obstante, en ocasiones, se reunían doce sueltas en un volumen semejante a una parte de comedias

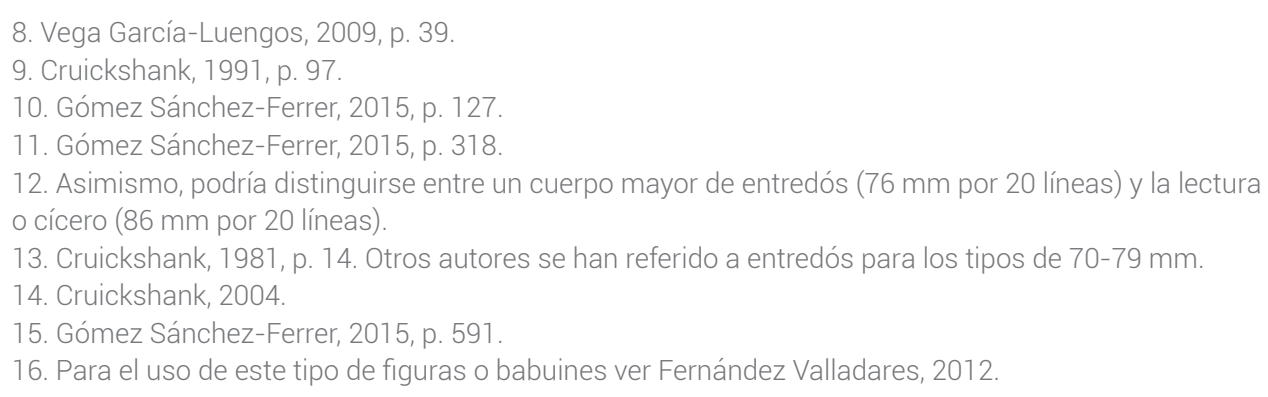


en el que se incorporaba una portada y una tabla de comedias ${ }^{17}$. A este respecto puede recordarse, por ejemplo, el Jardín ameno, una colección de 28 volúmenes de doce comedias cada uno, probablemente publicados en Madrid, que recoge una serie de comedias sueltas, integrada por más de 340 títulos $^{18}$.

Existieron diferentes tipos de sueltas teatrales, unas impresas de forma ordinaria y otras con motivo de ocasiones extraordinarias que, en ocasiones, adquieren un importante valor político y cultural. Tanto las primeras como las segundas han de considerarse también por su valor ecdótico ${ }^{19}$ así como sociológico ${ }^{20}$.

\subsection{La identificación de las comedias sueltas}

El correcto control del patrimonio bibliográfico ${ }^{21}$ de las comedias sueltas requiere llevar a cabo un proceso de identificación de cada uno de los testimonios que siga los presupuestos establecidos por Wilson ${ }^{22}$ en su pionero trabajo del año 1973. En él describía el conjunto de los distintos elementos que son comunes a todas las ediciones de comedias sueltas y que las caracteriza como formato editorial frente a otros impresos breves. A este respecto, Wilson explica que, más allá de los que constituyen una ficha de descripción básica (autor, título, lugar de impresión, nombre del impresor o del editor, fecha de publicación, paginación o foliación, formato y signaturas), los elementos que debemos considerar para la correcta identificación y distinción de unas ediciones frente a otras son los siguientes: la presencia o no de número de serie, la aparición o no de número en la primera página, la etiqueta genérica empleada (comedia famosa, la gran comedia...), la etiqueta sobre la autoría de la pieza, la etiqueta empleada para la indicación sobre los personajes (Hablan en ella las personas siguientes, Personas...), la organización de los dramatis personae en la primera página, el uso de la mayúscula al principio de la acotación inicial, la colación, los titulillos, el colofón, los reclamos, la tipografía, la ornamentación y aquellas características que puedan ser significativas relacionadas con la ortografía. A esto debe sumarse que las comedias sueltas suelen presentar uno o varios patrones de uso en cuanto a la tipografía y la ornamentación en función de la imprenta de la que provengan ${ }^{23}$. Así lo ha demostrado Wilson ${ }^{24}$ para el caso de la viuda del sevillano Francisco de Leefdael o bien para la imprenta de Orga en Valencia. En este sentido, debe tenerse en cuenta que no todas las imprentas contaban con las mismas veinte matrices, ni tampoco con iguales tacos de ornamentos o con semejantes letras mayúsculas iniciales.

\footnotetext{
17. Reichenberger, 1989, p. 289.

18. Reichenberger, 1989, p. 289.

19. Cruickshank, 1985, p. 68.

20. Moll, 1971, p. 259

21. Bainton, 1988, pp. 56-58.

22. Wilson, 1973, pp. 211-215.

23. Cruickshank, 2004, p. 973.

24. Wilson, 1973, pp. 215-216.
} 
Los distintos elementos mencionados por Wilson en combinación con los diferentes patrones de uso tipográfico y ornamental se erigen, por tanto, en elemento fundamental para la identificación de estos materiales impresos y pueden ayudarnos, además, a atribuir una suelta sin datos bibliográficos o con datos falsos a una imprenta concreta. Este constituye uno de los principales problemas bibliográficos que presenta el teatro del Siglo de Oro impreso en formato suelto ${ }^{25} \mathrm{y}$, asimismo, supone que desconozcamos la actividad de numerosos impresores además de la trayectoria de publicación, tanto en términos cronológicos como geográficos, de este tipo de materiales bibliográficos tan numerosos y de tal éxito. A este respecto, Vega García-Luengos ${ }^{26}$ ha indicado que las comedias sueltas que más interés suscitan, en cuanto a sus tiempos y espacios de fabricación, son las impresas en el siglo XVII, puesto que la mayor parte de ellas no llevan datos de imprenta. A diferencia de ellas, las del XVIII habitualmente cuentan con un colofón que las atribuye a una ciudad, a veces a una imprenta o librería y, en menos ocasiones, a una fecha concreta ${ }^{27}$. No obstante, a lo largo de esta centuria se localizan, asimismo, algunos proyectos editoriales, como el de Teresa de Guzmán, que presenta conjuntos de ediciones sueltas no identificadas.

El método más sencillo para identificar la fecha y taller impresor de una suelta que carezca de esta información bibliográfica consiste en identificar los elementos estructurales que Wilson menciona, así como trazar un esquema del material tipográfico y ornamental empleado. Solo después este podrá cotejarse con el usado en impresos indubitados ${ }^{28}$. Esta supone la metodología de trabajo empleada por aquellos investigadores que han trabajado en este campo y logrado atribuir, con éxito, comedias sueltas del siglo XVII, que carecían de información bibliográfica veraz, a un taller tipográfico concreto ${ }^{29}$. La investigación sobre la centuria siguiente en el mismo sentido ha sido más escasa, a pesar de ser todavía muchos los problemas de identificación que faltan por resolver. Merece la pena considerar, sin embargo, la dificultad de resolver los escollos bibliográficos que presentan las comedias sueltas de forma global. En primer lugar, no sabemos de forma certera cuáles y cuántas ediciones presentan problemas. En segundo, dado que no contamos con un repertorio bibliográfico dedicado exclusivamente a estos materiales editoriales en el que estos se describan de acuerdo con el esquema antes propuesto, no disponemos de una base de impresos indubitados amplia que nos permita hacer cotejos extensos para poder identificar aquellos sobre los cuales se tienen dudas.

25. Cruickshank y Varey, 1973

26. Vega García-Luengos, 2009, pp. 37-38.

27. Vega García-Luengos, 2009, p. 39.

28. Cruickshank, 1975, p. 73.

29. Cruickshank y Wilson, 1974; Wilson y Cruickshank, 1980, p. 40; Cruickshank, 1989, p. 251; Cardona, Cruickshank y Cunningham, en su ed. de La púrpura de la rosa, p. 515 y Vega García-Luengos, 2009, p. 37. 


\subsection{El control bibliográfico de las comedias sueltas}

Desde principios del siglo $x \mathrm{x}$ se han publicado varios trabajos de naturaleza diversa ${ }^{30}$ que se han ocupado, siempre parcialmente, de favorecer el control bibliográfico de estos impresos. Esas investigaciones han atendido al estudio de sueltas particulares, series de sueltas o conjuntos de sueltas conservadas en una misma institución. Entre finales del siglo xx y los primeros años del XXI, se propuso la reunión de estos testimonios bibliográficos en una herramienta informática de conjunto ${ }^{31}$ en la que se recopilase toda la información recogida hasta el momento en papel y, posteriormente, se permitiera incorporar las nuevas ediciones localizadas en bibliotecas no inventariadas. Este planteamiento desembocó en el pionero proyecto Comedias Sueltas USA ${ }^{32}$ que dirige Szilvia Szmuk ${ }^{33}$ y cuyo objetivo consiste en reunir las sueltas conservadas en bibliotecas académicas estadounidenses.

A pesar de la existencia de importantes publicaciones y proyectos como el mencionado, en el proceso de realización de esta investigación se constató la necesidad de crear una base de datos de sueltas teatrales anteriores a 1834 de acuerdo con la convención empleada en otros trabajos de factura semejante ${ }^{34}$. La falta de un recurso digital único en el que se congreguen las sueltas teatrales impresas desde el siglo XVI hasta la fecha señalada, conservadas en bibliotecas de todo el mundo, nos impide, a pesar de la importancia del género editorial, ofrecer cifras y datos precisos referidos, entre otras cuestiones, a los números totales de impresos publicados, los períodos, ciudades e imprentas de mayor producción, las relación entre impresores y editores, los porcentajes de sueltas sin datos de impresión o los autores y obras de mayor éxito. El hecho de no contar con una base de datos de estas características complica también, como antes hemos explicado, el trabajo de adscripción de una suelta cuando esta carece de datos bibliográficos. Estas dificultades son, precisamente, las que hemos detectado en el curso de nuestra investigación sobre las ediciones de comedias sueltas que financió la librera Teresa de Guzmán, tal y como a continuación de explicará.

30. Puede verse una exhaustiva recopilación de trabajos en: Comedias Sueltas USA, 15 junio 2019: <http://comediassueltasusa.com/comp-sources/>.

31. Bainton, 1988; Szmuk, 2001.

32. Comedias Sueltas USA, 15 junio 2019: <http://comediassueltasusa.com/>.

33. Quisiera agradecer a la Dra. Szilvia Szmuk su generosidad, pues me ha permitido el acceso a un número elevado de reproducciones digitales de las sueltas incluidas en su catálogo antes de que estas estén disponibles en línea.

34. Esta fecha puede explicarse tanto por cuestiones tipográficas, esto es, relacionadas con las transformaciones en el proceso de impresión, como por una serie de factores culturales. Entre estos destacan los cambios estéticos que se producen en esta fecha así como los históricos, de los que es ejemplo el fallecimiento del rey Fernando VII. 


\section{EL PROBLEMA BIBLIOGRÁFICO DE LAS SUELTAS FINANCIADAS POR TERESA DE GUZMÁN}

La Lonja de Comedias de la madrileña Puerta del Sol, situada a la entrada de la calle de las Carretas, estuvo en funcionamiento entre 1731 y 1786 o 1787. Durante ese período estuvo gestionada en tres etapas distintas por libreros diferentes - Teresa de Guzmán, Hipólito Rodríguez y Juan Romualdo Rodríguez- cuya relación está todavía por confirmar ${ }^{35}$. Particularmente interesante resulta la actividad de Teresa de Guzmán, por cuanto durante su regencia, comprendida entre 1733 y 1737, la Lonja de Comedias de la Puerta del Sol jugó un extraordinario papel en la edición y venta de comedias del Siglo de Oro en la capital madrileña. Entre las fechas mencionadas la librera solicitó licencia para la impresión de sesenta y una ediciones de obras teatrales del Siglo de Oro ${ }^{36}$. A saber: nueve comedias de Lope de Vega, treinta y siete comedias de Tirso de Molina, doce de Ruiz de Alarcón, una de Pérez de Montalbán, una de Vélez de Guevara y otra de Hoz y Mota. No parece que finalmente todas se hayan impreso, pues solo hemos encontrado prueba bibliográfica de cincuenta y tres sueltas de las obras citadas tal y como es posible observar en la Tabla I.

Aunque, como antes hemos indicado, la edición de teatro en suelta predominó durante todo el siglo XVIII, este formato convivió con algunos ejemplos de partes de doce comedias. El proyecto editorial de Teresa de Guzmán es ejemplo de dicha armonía, pues, entre las licencias de impresión localizadas en el Archivo Histórico Nacional a nombre de la librera, se encuentra una en la que solicita la aprobación para la publicación de dos partes de comedias de Lope de Vega que, sin embargo, no parecen haber llegado nunca a la imprenta ${ }^{37}$. Otro ejemplo de su interés por las partes de comedias es el que nos ofrecen las tres partes facticias de comedias de Tirso que puso a la venta en 1734 y 1736 y que fueron producto de la reunión de treinta seis sueltas de las mandadas publicar durante los años anteriores.

En la Tabla $\left.\right|^{38}$ se recogen los datos bibliográficos fundamentales de las cincuenta y tres sueltas, así como de las tres partes de comedias que Teresa de Guzmán financió ordenadas cronológicamente desde 1733 a 173739 . Este corpus nos indica la preferencia de la librera por Tirso de Molina durante los años 1733 y 1734 y su inclinación posterior hacia la edición de Ruiz de Alarcón desde el año 1735 en adelante.

Sabemos que Teresa de Guzmán solicitó licencia de impresión y tasa para los títulos de las cincuenta y tres comedias editadas recogidas en la Tabla I. Todas estas ediciones presentan diferencias tanto en sus características tipográficas como

35. Ulla Lorenzo, 2018.

36. Ulla Lorenzo, 2016.

37. Ulla Lorenzo, 2016, p. 238.

38. Para facilitar la lectura del trabajo, esta y las siguientes tablas se incorporan en un anexo final.

39. Ninguna de las ediciones sueltas presenta fecha de publicación, por tal motivo estas se incluyen entre corchetes. Se trata de una propuesta de fechas aproximadas a partir de las licencias de impresión y venta que Teresa de Guzmán solicita para ellas así como de su anuncio en la Gaceta de Madrid (Ulla Lorenzo, 2016) 
en lo que se refiere a su información bibliográfica, por lo que suponemos que salieron de talleres diferentes. De acuerdo con la información recogida en la Tabla I, no todas las ediciones Ilevan el nombre de Teresa de Guzmán en el colofón en tanto que editora y librera: tres de ellas corresponden a comedias para las cuales se solicitó licencia en 1735 y que quizás no se imprimieron hasta más tarde, cuando ya Teresa de Guzmán había abandonado el proyecto editorial. Es posible también que estas sean reediciones realizadas en una etapa posterior de la lonja y no se hayan conservado las impresas en tiempos de la librera. Se trata de tres sueltas de comedias de Ruiz de Alarcón: La amistad castigada, La manganilla de Melilla y El dueño de las estrellas. Las cuatro ediciones restantes que no llevan su nombre debieron de imprimirse después de 1737, pues Teresa de Guzmán no solicita su licencia hasta diciembre de ese año y, seguramente, salieron sin su nombre porque su participación finaliza precisamente tras solicitar esa última licencia. En este caso el grupo está compuesto por sueltas de comedias a nombre de Lope de Vega: La reina Juana de Nápoles, Servir con mala estrella, La dama boba y Los melindres de Belisa.

De las cuarenta y seis ediciones restantes, cuarenta presentan como lugar de impresión Madrid y las otras seis no aportan información a este respecto. Sin embargo, de las cuarenta que muestran una localización geográfica solo tres ediciones tienen nombre del impresor. El primero de ellos es José González. Este impresor madrileño trabajó aproximadamente entre 1729-1763 en la Calle del Arenal y colaboró con Teresa de Guzmán en la publicación de La lindona de Galicia de Pérez de Montalbán y de Amar por señas de Tirso de Molina, ambas de 1733. El segundo impresor que se menciona en el grupo de sueltas es Juan de Ariztia, quien trabajó entre 1712-1741 en la calle de Alcalá y se hizo cargo de la impresión de Cómo han de ser los amigos de Tirso en el año 1734. Además de José González y Juan de Ariztia, sabemos que Teresa de Guzmán pudo relacionarse con otros impresores de sueltas de distintos puntos de la Península cuando se hizo cargo de la librería de la lonja en $1733^{40}$. Así pues, el negocio de Teresa de Guzmán y sus relaciones con otros miembros del gremio dan buena cuenta de la existencia de un activo mercado del libro teatral en la ciudad de Madrid, pero también a nivel peninsular. Por tal motivo, parecía interesante tratar de identificar la imprenta de la que habían salido aquellas ediciones que carecían de esta información, de manera que lográramos así reconstruir el mapa de relaciones de Teresa de Guzmán.

\subsection{Notas para la identificación de las sueltas financiadas por Teresa de Guzmán}

Con este objetivo, se trazó un listado de todas las imprentas de la Península de las cuales salieron ediciones de comedias sueltas entre 1700 y $1750^{47}$, con el fin de ampliar los márgenes cronológicos de trabajo de nuestra librera. De tal tarea obtuvimos un resultado de 41 impresores que se relacionan, organizados alfabética-

40. Ulla Lorenzo, 2016, pp. 240-241.

41. Para confeccionar este listado se ha hecho uso del Catálogo Colectivo del Patrimonio Bibliográfico Español, 15 junio de 2019: <http://catalogos.mecd.es/CCPB/ccpbopac/>. 
mente según su apellido, en la Tabla II. La información que se recoge en esta tabla nos permite señalar la importancia de la ciudad de Madrid como centro impresor del género dramático en la primera mitad del siglo XVIII, pues cuenta con un total de dieciséis talleres; a esta le sigue Sevilla con ocho, Barcelona con seis, Burgos, Córdoba y Salamanca con dos y, finalmente, Alcalá, Cervera, Valencia, Valladolid y Zaragoza con uno.

Posteriormente, se revisó manualmente un conjunto de aproximadamente 10.000 sueltas digitalizadas ${ }^{42}$ y se localizaron entre una y cinco sueltas teatrales de cada una de las imprentas citadas en la tabla. A continuación, se identificaron sus elementos estructurales principales de acuerdo con los mencionados por Wilson. Estos se recogieron en una sencilla base de datos relacional de Microsoft Access. Con este paso tratábamos de reunir un grupo de textos indubitados coetáneos a los financiados por Teresa de Guzmán para poder localizar en ellos aquellos elementos que nos ayudaran a atribuir las sueltas vendidas en la Lonja de Comedias que, previamente, habíamos incluido también en nuestra base de datos y desgranado en sus componentes estructurales fundamentales. Una vez reunido el conjunto de impresores coetáneos a doña Teresa, seleccionado e identificado el corpus de ediciones de sueltas que cada uno de ellos publicó, fue posible realizar las identificaciones iniciales que nos ayudan a ampliar o profundizar en las relaciones comerciales de la librera con otros profesionales del gremio.

El primer ejemplo que exponemos se relaciona con la localización de una nueva emisión de una de las ediciones financiadas por Teresa de Guzmán impresa de Zaragoza. Dicha identificación ha sido posible gracias a la coincidencia del número de serie, los tipos de letra empleados en cada sección, la ausencia de una mayúscula en redonda al principio de la acotación inicial así como del filete que separa la cabecera del texto y las dos columnas de texto. Esto es, gracias a la coincidencia de algunos de los elementos tipo que señala Wilson entre dos sueltas de nuestra base de datos. Como ejemplo podemos ver las portadas exactamente iguales de Los melindres de Belisa (con título La dama melindrosa en la suelta) que se reproducen: una de las emisiones lleva pie de imprenta de Madrid y otra de Zaragoza, concretamente de la imprenta que está en la Plaza del Carbón sobre el Peso Real (Figuras 1 y 2).

42. Debe considerarse la ventaja de disponer en la actualidad de fondos bibliográficos de sueltas digitalizados. Se han consultado las ofrecidas por Google Books y las bibliotecas digitales de la Universidad de Sevilla, Biblioteca Nacional de España y la Österreichische Nationalbibliothek de Viena. A ellas deben sumarse las revisadas gracias a la amabilidad de Szilvia Szmuk. 


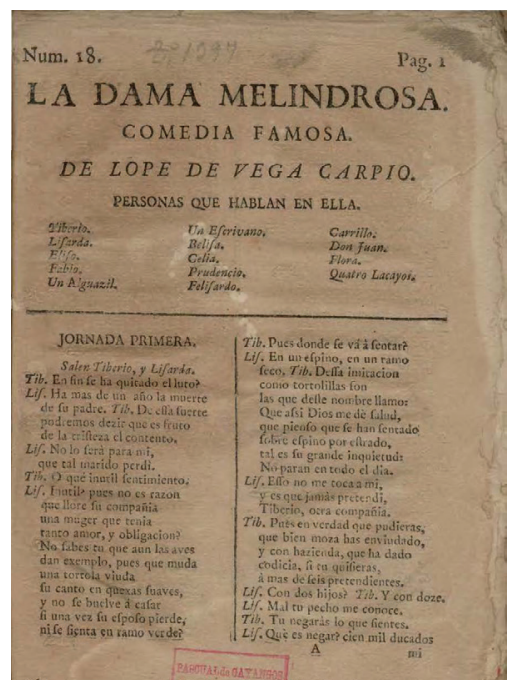

Figura 1 Lope de Vega, La dama melindrosa Madrid, Lonja de Comedias de la Puerta del Sol [1737]

(c) Biblioteca Nacional de España (T/14802/6) La imagen se ha tomado de la Biblioteca

Digital Hispánica: <http://bdh-rd.bne.es/viewer. $v m ?$ id $=0000058720 \&$ page $=1>$

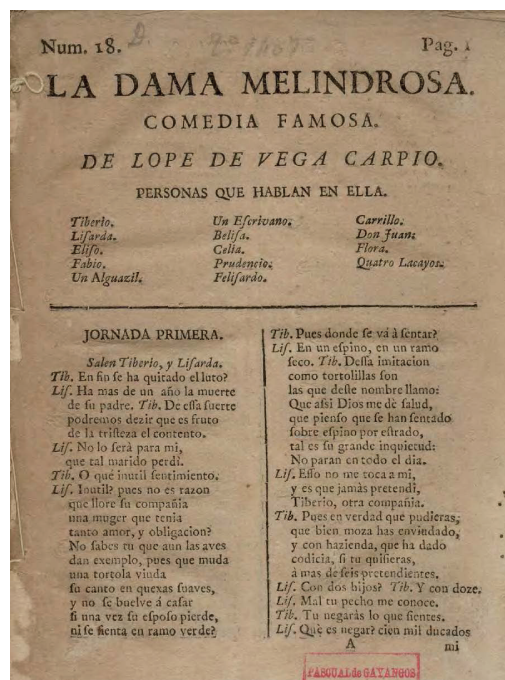

Figura 2 Lope de Vega, La dama melindrosa, Zaragoza, Imprenta que está en la plaza del Carbón, s.d.

(c) Biblioteca Nacional de España (T/14809/23). La imagen se ha tomado de la Biblioteca Digital Hispánica: <http://bdh-rd.bne.es/viewer. vm?id=0000059060\&page $=1>$

Esta circunstancia nos ayudaría a vincular a la librera madrileña con la imprenta zaragozana. A partir de este ejemplo, además, se pudo identificar también la suelta de La dama boba (con título La boba discreta), de la que también se conservan dos emisiones: una en Madrid y otra en Zaragoza publicada a cargo de la misma imprenta.

El segundo caso que aportamos está relacionado con la atribución de 22 de las ediciones sin datos de impresión a un taller tipográfico concreto gracias del uso recurrente de un determinado elemento ornamental -el florón (3. en este caso-, la medida de los tipos y el empleo de un tipo de cursiva en varias ediciones sueltas. Para lograr este propósito, se seleccionaron, en primer lugar, las 22 ediciones financiadas por Teresa de Guzmán que presentaban el elemento ornamental mencionado con diferentes disposiciones. Estas se recogen en la Tabla III.

La búsqueda en nuestra base de datos nos indica que fueron nueve los impresores de la Península que manejaron dicho recurso ornamental tal y como se expone en la Tabla IV. Tres de ellos han de quedar fuera del cómputo puesto que no trabajan en el arco de fechas que nos interesa. Se trata de Ignacio Guasch, Juan Sanz y Francisco García de Onorato. Dispondríamos, por tanto, de un listado de seis posibles impresores madrileños de cuyos talleres pudieron salir las sueltas que doña Teresa financió.

No obstante, si medimos los milímetros de los tipos en los veinte renglones de una página de una suelta modelo salida de cada imprenta, vemos que las medidas 
más características de cada una de estas imprentas son bien del tipo filosofía, bien del tipo cícero o lectura. Este dato es muy significativo, puesto que las 22 sueltas de Teresa de Guzmán que presentan el florón se caracterizan por el uso de tipos de 75 milímetros, es decir, filosofía, lo cual acerca las sueltas de Teresa de Guzmán a los talleres de Juan de Ariztia, José González - con los que sabemos que trabajó en otras ocasiones - y Antonio Sanz (Tabla V). Mientras que aleja las ediciones de los restantes talleres que antes se citaban, puesto que estos hicieron uso del tipo cícero o lectura.

Si regresamos a los restantes criterios que menciona Wilson veremos que algunos de ellos son significativos en este caso concreto. Interesa señalar que las 22 sueltas de Teresa de Guzmán que estamos examinando presentan una estructura en la que se suceden la etiqueta COMEDIA FAMOSA, seguida del título, ambos en redonda; después el nombre del autor en cursiva; la indicación PERSONAS QUE HABLAN EN ELLA en redonda, la lista de dramatis personae en cursiva y, finalmente, la indicación de JORNADA PRIMERA en redonda. Esta misma estructura es la que siguen las sueltas de Juan de Ariztia y de Antonio Sanz pero no las de José González, en las que se omite la indicación de jornada y no se combinan las redondas y cursivas de igual forma. Es posible observar esta cuestión en las Figuras 3 y 4, en las que se compara una de las sueltas de Teresa de Guzmán con una salida del taller de José González.

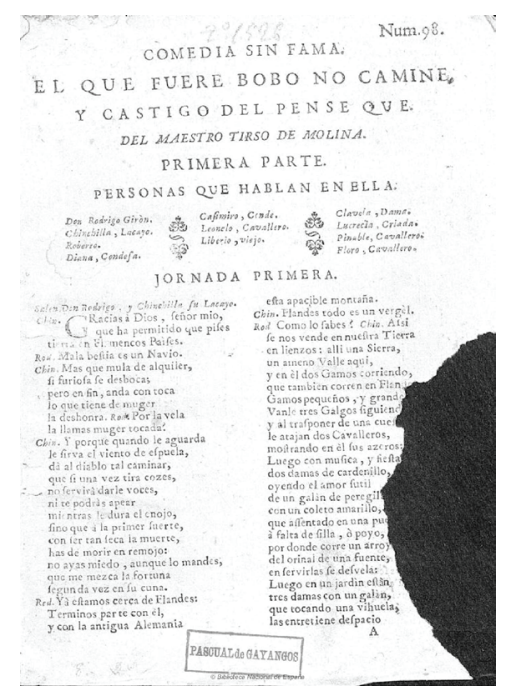

Figura 3 Tirso de Molina, El que fuere bobo no camine y castigo del pensé que, Madrid, s.n., a costa de Teresa de Guzmán, [1734]. (c) Biblioteca Nacional de España (T/15004/16);

la imagen se ha tomado de la Biblioteca

Digital Hispánica: <http://bdh-rd.bne.es/viewer. $v m ? i d=0000171536 \&$ page $=1>$

\section{COMEDIA NUEVA. EL DUENDE DE ZARAGOZA.}

COMPUESTA POR DON Thomàs de Añorbe y Correjel, Capellan del Real Monafterio de la Encarnacion de Madrid. ANNO DE: MDCCXXXIV: 1734

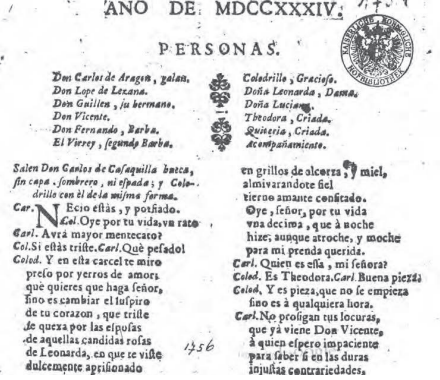

Figura 4 Tomás de Añorbe, El duende de Zaragoza, Madrid, José González, 1734. (c) Google Books: <https://goo.gl/ktC95K> 
Asimismo, podemos fijarnos en la tipografía de la cursiva, más significativa que la redonda como antes se indicaba, y percibir cómo los tres impresores usan tipos diferentes para la u mayúscula cursiva del indefinido "un" que figura en los dramatis personae. El que coincide con el uso que figura en las sueltas de Teresa de Guzmán es el de Juan de Ariztia. Parece que ni José González ni Antonio Sanz tenían dicha letra, por lo que empleaban otro tipo de u tal y como se observa en la Tabla VI.

Así pues, si antes señalábamos que Juan de Ariztia había impreso en 1734 la suelta de la comedia de Tirso de Molina titulada Cómo han de ser los amigos, ahora podemos proponer que la relación entre el impresor y la librera comenzó ya en 1733 y se alargó hasta 1736. Durante ese arco de fechas el tipógrafo madrileño publicó un conjunto amplio de sueltas que doña Teresa financió y, más tarde, vendió en su lonja.

\section{CONCLUSIONES}

De acuerdo con lo expuesto a lo largo de este artículo, no parece haber duda de que la existencia de un repositorio de conjunto que permitiera censar todas las ediciones teatrales sueltas facilitaría la identificación de aquellas sin datos de publicación, de las que son ejemplo en este trabajo un fragmento del conjunto de las financiadas por Teresa de Guzmán. Este repositorio debiera contener un modelo de descripción bibliográfica que siga los presupuestos enumerados por Wilson, de forma que pudiéramos recuperar en una sola búsqueda, y ayudándonos de los filtros pertinentes, la información deseada sobre cualquiera de los elementos que constituyen la descripción. Asimismo, sería fundamental poder aportar una reproducción de su portada que, en muchos casos, nos ayudaría a solventar el problema de identificación de un solo vistazo.

Un recurso de estas características podría aprovecharse, sin duda, de las ventajas que nos ofrece la tecnología para el tratamiento de los grandes conjuntos de información en el campo de las humanidades. Esto nos permitiría poder vincular las entradas de la base de datos con un software de reconocimiento visual que nos ayudara a localizar la tipografía y los elementos ornamentales -sean estos tipográficos, marcas de impresor o letras ornadas - presentes en la suelta que deseemos identificar en otras sueltas recogidas en el recurso ${ }^{43}$.

Un proyecto de esta naturaleza, que cense e identifique las sueltas teatrales, podría contribuir a resolver los problemas de atribución tipográfica propios del género editorial de la suelta como el expuesto en relación al proyecto editorial de Teresa de Guzmán. A este respecto hemos podido descubrir, como muestra del buen funcionamiento de esta metodología, las relaciones de la librera madrileña con la imprenta zaragozana del Peso; así como constatar aquellas establecidas con el taller madrileño de Juan de Ariztia, con el cual colaboró durante un período más extenso de lo que, hasta el momento, conocíamos. 
Si alejamos el foco del problema concreto de las adscripciones tipográficas, el recurso de conjunto planteado nos permitiría entender de una forma más clara el sistema de funcionamiento del comercio de los pliegos teatrales. A través de él podríamos conocer quiénes fueron los impresores de este género y en qué fechas trabajaron. Esta herramienta nos ofrecería datos sobre cuáles fueron los centros tipográficos de mayor importancia. Por último, podríamos averiguar cómo se establecían las relaciones entre los libreros y los impresores a nivel peninsular pero también con respecto a la actividad editorial de las prensas americanas.

Finalmente, un recurso de estas características nos ayudaría a evidenciar las relaciones entre la imprenta y la escena, si es que las hubo en todos los casos, pero también las tendencias de lectura y los gustos de los receptores y, por supuesto, la frecuencia de edición del teatro áureo frente al compuesto en el siglo XVIII y, por tanto, la pervivencia de la comedia clásica a lo largo de la centuria y a ambos lados del Atlántico.

\section{ANEXOS}

\begin{tabular}{|c|c|c|c|c|c|c|}
\hline Título & Autor & Editor & Lugar & Fecha & Impresor & Librero \\
\hline $\begin{array}{l}\text { La república } \\
\text { al revés }\end{array}$ & $\begin{array}{l}\text { Tirso } \\
\text { de Molina }\end{array}$ & $\begin{array}{l}\text { Teresa } \\
\text { de Guzmán }\end{array}$ & Madrid & [1733] & s.n. & $\begin{array}{l}\text { Lonja de } \\
\text { Comedias }\end{array}$ \\
\hline $\begin{array}{l}\text { La villana de } \\
\text { la sagra }\end{array}$ & $\begin{array}{l}\text { Tirso } \\
\text { de Molina }\end{array}$ & $\begin{array}{l}\text { Teresa de } \\
\text { Guzmán }\end{array}$ & Madrid & [1733] & s.n. & $\begin{array}{l}\text { Lonja de } \\
\text { Comedias }\end{array}$ \\
\hline $\begin{array}{l}\text { Celos con } \\
\text { celos se curan }\end{array}$ & $\begin{array}{l}\text { Tirso } \\
\text { de Molina }\end{array}$ & $\begin{array}{l}\text { Teresa de } \\
\text { Guzmán }\end{array}$ & s.l. & [1733] & s.n. & $\begin{array}{l}\text { Lonja de } \\
\text { Comedias }\end{array}$ \\
\hline $\begin{array}{l}\text { Esto sí que } \\
\text { es negociar }\end{array}$ & $\begin{array}{l}\text { Tirso } \\
\text { de Molina }\end{array}$ & $\begin{array}{l}\text { Teresa de } \\
\text { Guzmán }\end{array}$ & s.l. & [1733] & s.n. & $\begin{array}{l}\text { Lonja de } \\
\text { Comedias }\end{array}$ \\
\hline El amor médico & $\begin{array}{l}\text { Tirso } \\
\text { de Molina }\end{array}$ & $\begin{array}{l}\text { Teresa de } \\
\text { Guzmán }\end{array}$ & Madrid & [1733] & s.n. & $\begin{array}{l}\text { Lonja de } \\
\text { Comedias }\end{array}$ \\
\hline $\begin{array}{l}\text { La lindona } \\
\text { de Galicia }\end{array}$ & $\begin{array}{l}\text { Pérez de } \\
\text { Montalbán, } \\
\text { Juan }\end{array}$ & $\begin{array}{l}\text { Teresa de } \\
\text { Guzmán }\end{array}$ & Madrid & [1733] & $\begin{array}{l}\text { José } \\
\text { González }\end{array}$ & $\begin{array}{l}\text { Lonja de } \\
\text { Comedias }\end{array}$ \\
\hline Amar por señas & $\begin{array}{l}\text { Tirso } \\
\text { de Molina }\end{array}$ & $\begin{array}{l}\text { Teresa de } \\
\text { Guzmán }\end{array}$ & Madrid & [1733] & $\begin{array}{l}\text { José } \\
\text { González }\end{array}$ & $\begin{array}{l}\text { Lonja de } \\
\text { Comedias }\end{array}$ \\
\hline $\begin{array}{l}\text { El castigo de } \\
\text { la miseria }\end{array}$ & $\begin{array}{l}\text { Hoz y } \\
\text { Mota, } \\
\text { Juan de la }\end{array}$ & $\begin{array}{l}\text { Teresa de } \\
\text { Guzmán }\end{array}$ & Madrid & [1734] & s.n. & $\begin{array}{l}\text { Lonja de } \\
\text { Comedias }\end{array}$ \\
\hline $\begin{array}{l}\text { El castigo del } \\
\text { pensé qué II }\end{array}$ & $\begin{array}{l}\text { Tirso } \\
\text { de Molina }\end{array}$ & $\begin{array}{l}\text { Teresa de } \\
\text { Guzmán }\end{array}$ & Madrid & [1734] & S.n. & $\begin{array}{l}\text { Lonja de } \\
\text { Comedias }\end{array}$ \\
\hline $\begin{array}{l}\text { La gallega } \\
\text { Mari-Hernández }\end{array}$ & $\begin{array}{l}\text { Tirso } \\
\text { de Molina }\end{array}$ & $\begin{array}{l}\text { Teresa de } \\
\text { Guzmán }\end{array}$ & Madrid & [1734] & s.n. & $\begin{array}{l}\text { Lonja de } \\
\text { Comedias }\end{array}$ \\
\hline $\begin{array}{l}\text { Primera parte } \\
\text { de comedias } \\
\text { verdaderas del } \\
\text { Maestro Tirso } \\
\text { de Molina }\end{array}$ & $\begin{array}{l}\text { Tirso } \\
\text { de Molina }\end{array}$ & $\begin{array}{l}\text { Teresa de } \\
\text { Guzmán }\end{array}$ & & [1734] & s.n. & $\begin{array}{l}\text { Lonja de } \\
\text { Comedias }\end{array}$ \\
\hline
\end{tabular}




\begin{tabular}{|c|c|c|c|c|c|c|}
\hline Título & Autor & Editor & Lugar & Fecha & Impresor & Librero \\
\hline $\begin{array}{l}\text { No hay peor } \\
\text { sordo }\end{array}$ & $\begin{array}{l}\text { Tirso } \\
\text { de Molina }\end{array}$ & $\begin{array}{l}\text { Teresa de } \\
\text { Guzmán }\end{array}$ & s.l. & [1734] & s.n. & $\begin{array}{l}\text { Lonja de } \\
\text { Comedias }\end{array}$ \\
\hline Marta la piadosa & $\begin{array}{l}\text { Tirso } \\
\text { de Molina }\end{array}$ & $\begin{array}{l}\text { Teresa de } \\
\text { Guzmán }\end{array}$ & Madrid & [1734] & s.n. & $\begin{array}{l}\text { Lonja de } \\
\text { Comedias }\end{array}$ \\
\hline $\begin{array}{l}\text { El celoso } \\
\text { prudente }\end{array}$ & $\begin{array}{l}\text { Tirso } \\
\text { de Molina }\end{array}$ & $\begin{array}{l}\text { Teresa de } \\
\text { Guzmán }\end{array}$ & s.l. & [1734] & s.n. & $\begin{array}{l}\text { Lonja de } \\
\text { Comedias }\end{array}$ \\
\hline $\begin{array}{l}\text { El vergonzoso } \\
\text { en Palacio }\end{array}$ & $\begin{array}{l}\text { Tirso } \\
\text { de Molina }\end{array}$ & $\begin{array}{l}\text { Teresa de } \\
\text { Guzmán }\end{array}$ & Madrid & [1734] & s.n. & $\begin{array}{l}\text { Lonja de } \\
\text { Comedias }\end{array}$ \\
\hline $\begin{array}{l}\text { Don Gil de } \\
\text { las calzas } \\
\text { verdes }\end{array}$ & $\begin{array}{l}\text { Tirso } \\
\text { de Molina }\end{array}$ & $\begin{array}{l}\text { Teresa de } \\
\text { Guzmán }\end{array}$ & s.l. & [1734] & s.n. & $\begin{array}{l}\text { Lonja de } \\
\text { Comedias }\end{array}$ \\
\hline $\begin{array}{l}\text { El castigo del } \\
\text { pensé qué I }\end{array}$ & $\begin{array}{l}\text { Tirso } \\
\text { de Molina }\end{array}$ & $\begin{array}{l}\text { Teresa de } \\
\text { Guzmán }\end{array}$ & Madrid & [1734] & s.n. & $\begin{array}{l}\text { Lonja de } \\
\text { Comedias }\end{array}$ \\
\hline $\begin{array}{l}\text { Ventura te dé } \\
\text { Dios, hijo }\end{array}$ & $\begin{array}{l}\text { Tirso } \\
\text { de Molina }\end{array}$ & $\begin{array}{l}\text { Teresa de } \\
\text { Guzmán }\end{array}$ & Madrid & [1734] & s.n. & $\begin{array}{l}\text { Lonja de } \\
\text { Comedias }\end{array}$ \\
\hline $\begin{array}{l}\text { Cómo han de } \\
\text { ser los amigos }\end{array}$ & $\begin{array}{l}\text { Tirso } \\
\text { de Molina }\end{array}$ & $\begin{array}{l}\text { Teresa de } \\
\text { Guzmán }\end{array}$ & Madrid & [1734] & $\begin{array}{l}\text { Juan de } \\
\text { Ariztia }\end{array}$ & $\begin{array}{l}\text { Lonja de } \\
\text { Comedias }\end{array}$ \\
\hline $\begin{array}{l}\text { El amor y la } \\
\text { amistad }\end{array}$ & $\begin{array}{l}\text { Tirso } \\
\text { de Molina }\end{array}$ & $\begin{array}{l}\text { Teresa de } \\
\text { Guzmán }\end{array}$ & s.l. & [1734] & s.n. & $\begin{array}{l}\text { Lonja de } \\
\text { Comedias }\end{array}$ \\
\hline $\begin{array}{l}\text { Antes que te } \\
\text { cases mira lo } \\
\text { que haces y } \\
\text { examen de } \\
\text { maridos }\end{array}$ & $\begin{array}{l}\text { Ruiz de } \\
\text { Alarcón, } \\
\text { Juan }\end{array}$ & $\begin{array}{l}\text { Teresa de } \\
\text { Guzmán }\end{array}$ & Madrid & [1735] & s.n. & $\begin{array}{l}\text { Lonja de } \\
\text { Comedias }\end{array}$ \\
\hline $\begin{array}{l}\text { La crueldad } \\
\text { por el honor }\end{array}$ & $\begin{array}{l}\text { Ruiz de } \\
\text { Alarcón, } \\
\text { Juan }\end{array}$ & $\begin{array}{l}\text { Teresa de } \\
\text { Guzmán }\end{array}$ & Madrid & [1735] & s.n. & $\begin{array}{l}\text { Lonja de } \\
\text { Comedias }\end{array}$ \\
\hline $\begin{array}{l}\text { Lo que mucho } \\
\text { vale mucho } \\
\text { cuesta en } \\
\text { ganar amigos }\end{array}$ & $\begin{array}{l}\text { Ruiz de } \\
\text { Alarcón, } \\
\text { Juan }\end{array}$ & $\begin{array}{l}\text { Teresa de } \\
\text { Guzmán }\end{array}$ & Madrid & [1735] & s.n. & $\begin{array}{l}\text { Lonja de } \\
\text { Comedias }\end{array}$ \\
\hline $\begin{array}{l}\text { Los empeños } \\
\text { de un engaño }\end{array}$ & $\begin{array}{l}\text { Ruiz de } \\
\text { Alarcón, } \\
\text { Juan }\end{array}$ & $\begin{array}{l}\text { Teresa de } \\
\text { Guzmán }\end{array}$ & Madrid & [1735] & s.n. & $\begin{array}{l}\text { Lonja de } \\
\text { comedias }\end{array}$ \\
\hline $\begin{array}{l}\text { La amistad } \\
\text { castigada }\end{array}$ & $\begin{array}{l}\text { Ruiz de } \\
\text { Alarcón, } \\
\text { Juan }\end{array}$ & s.n. & s.l. & [1735] & s.n. & $\begin{array}{l}\text { Lonja de } \\
\text { Comedias }\end{array}$ \\
\hline $\begin{array}{l}\text { La manganilla } \\
\text { de Melilla }\end{array}$ & $\begin{array}{l}\text { Ruiz de } \\
\text { Alarcón, } \\
\text { Juan }\end{array}$ & s.n. & Madrid & [1735] & s.n. & $\begin{array}{l}\text { Lonja de } \\
\text { Comedias }\end{array}$ \\
\hline $\begin{array}{l}\text { Del mal el } \\
\text { menos y } \\
\text { averígüelo } \\
\text { Vargas }\end{array}$ & $\begin{array}{l}\text { Tirso } \\
\text { de Molina }\end{array}$ & $\begin{array}{l}\text { Teresa de } \\
\text { Guzmán }\end{array}$ & Madrid & [1735] & s.n. & $\begin{array}{l}\text { Lonja de } \\
\text { Comedias }\end{array}$ \\
\hline
\end{tabular}




\begin{tabular}{|c|c|c|c|c|c|c|}
\hline Título & Autor & Editor & Lugar & Fecha & Impresor & Librero \\
\hline $\begin{array}{l}\text { El petimetre } \\
\text { con palabras } \\
\text { y plumas }\end{array}$ & $\begin{array}{l}\text { Tirso } \\
\text { de Molina }\end{array}$ & $\begin{array}{l}\text { Teresa de } \\
\text { Guzmán }\end{array}$ & Madrid & [1735] & s.n. & $\begin{array}{l}\text { Lonja de } \\
\text { Comedias }\end{array}$ \\
\hline $\begin{array}{l}\text { Favorecer a } \\
\text { todos y no } \\
\text { amar a ninguna }\end{array}$ & $\begin{array}{l}\text { Tirso } \\
\text { de Molina }\end{array}$ & $\begin{array}{l}\text { Teresa de } \\
\text { Guzmán }\end{array}$ & Madrid & [1735] & s.n. & $\begin{array}{l}\text { Lonja de } \\
\text { Comedias }\end{array}$ \\
\hline $\begin{array}{l}\text { La mujer que } \\
\text { manda en casa }\end{array}$ & $\begin{array}{l}\text { Tirso } \\
\text { de Molina }\end{array}$ & $\begin{array}{l}\text { Teresa de } \\
\text { Guzmán }\end{array}$ & Madrid & [1735] & s.n. & $\begin{array}{l}\text { Lonja de } \\
\text { Comedias }\end{array}$ \\
\hline $\begin{array}{l}\text { La nuera más } \\
\text { leal y mejor } \\
\text { espigadera }\end{array}$ & $\begin{array}{l}\text { Tirso } \\
\text { de Molina }\end{array}$ & $\begin{array}{l}\text { Teresa de } \\
\text { Guzmán }\end{array}$ & Madrid & [1735] & s.n. & $\begin{array}{l}\text { Lonja de } \\
\text { Comedias }\end{array}$ \\
\hline $\begin{array}{l}\text { La prudencia } \\
\text { en la mujer }\end{array}$ & $\begin{array}{l}\text { Tirso } \\
\text { de Molina }\end{array}$ & $\begin{array}{l}\text { Teresa de } \\
\text { Guzmán }\end{array}$ & Madrid & [1735] & s.n. & $\begin{array}{l}\text { Lonja de } \\
\text { Comedias }\end{array}$ \\
\hline $\begin{array}{l}\text { El dueño de } \\
\text { las estrellas }\end{array}$ & $\begin{array}{l}\text { Ruiz de } \\
\text { Alarcón, } \\
\text { Juan }\end{array}$ & s.n. & s.l. & [1735] & s.n. & $\begin{array}{l}\text { Lonja de } \\
\text { Comedias }\end{array}$ \\
\hline $\begin{array}{l}\text { El amigo por } \\
\text { fuerza }\end{array}$ & $\begin{array}{l}\text { Lope } \\
\text { de Vega }\end{array}$ & $\begin{array}{l}\text { Teresa de } \\
\text { Guzmán }\end{array}$ & Madrid & [1735] & s.n. & $\begin{array}{l}\text { Lonja de } \\
\text { Comedias }\end{array}$ \\
\hline $\begin{array}{l}\text { Amar por } \\
\text { razón de estado }\end{array}$ & $\begin{array}{l}\text { Tirso } \\
\text { de Molina }\end{array}$ & $\begin{array}{l}\text { Teresa de } \\
\text { Guzmán }\end{array}$ & Madrid & [1735] & s.n. & $\begin{array}{l}\text { Lonja de } \\
\text { Comedias }\end{array}$ \\
\hline $\begin{array}{l}\text { La batalla del } \\
\text { honor }\end{array}$ & $\begin{array}{l}\text { Lope } \\
\text { de Vega }\end{array}$ & $\begin{array}{l}\text { Teresa de } \\
\text { Guzmán }\end{array}$ & Madrid & [1735] & s.n. & $\begin{array}{l}\text { Lonja de } \\
\text { Comedias }\end{array}$ \\
\hline $\begin{array}{l}\text { La obediencia } \\
\text { laureada }\end{array}$ & $\begin{array}{l}\text { Lope } \\
\text { de Vega }\end{array}$ & $\begin{array}{l}\text { Teresa de } \\
\text { Guzmán }\end{array}$ & Madrid & [1735] & s.n. & $\begin{array}{l}\text { Lonja de } \\
\text { Comedias }\end{array}$ \\
\hline $\begin{array}{l}\text { La prueba } \\
\text { de las promesas }\end{array}$ & $\begin{array}{l}\text { Ruiz de } \\
\text { Alarcón, } \\
\text { Juan }\end{array}$ & $\begin{array}{l}\text { Teresa de } \\
\text { Guzmán }\end{array}$ & Madrid & [1735] & s.n. & $\begin{array}{l}\text { Lonja de } \\
\text { Comedias }\end{array}$ \\
\hline $\begin{array}{l}\text { Nunca poco } \\
\text { costó mucho } \\
\text { y los pechos } \\
\text { privilegiados }\end{array}$ & $\begin{array}{l}\text { Ruiz de } \\
\text { Alarcón, } \\
\text { Juan }\end{array}$ & $\begin{array}{l}\text { Teresa de } \\
\text { Guzmán }\end{array}$ & Madrid & [1735] & s.n. & $\begin{array}{l}\text { Lonja de } \\
\text { Comedias }\end{array}$ \\
\hline $\begin{array}{l}\text { Privar contra } \\
\text { su gusto }\end{array}$ & $\begin{array}{l}\text { Tirso } \\
\text { de Molina }\end{array}$ & $\begin{array}{l}\text { Teresa de } \\
\text { Guzmán }\end{array}$ & Madrid & [1735] & s.n. & $\begin{array}{l}\text { Lonja de } \\
\text { Comedias }\end{array}$ \\
\hline $\begin{array}{l}\text { El pretendiente } \\
\text { al revés }\end{array}$ & $\begin{array}{l}\text { Tirso } \\
\text { de Molina }\end{array}$ & $\begin{array}{l}\text { Teresa de } \\
\text { Guzmán }\end{array}$ & Madrid & [1735] & s.n. & $\begin{array}{l}\text { Lonja de } \\
\text { Comedias }\end{array}$ \\
\hline $\begin{array}{l}\text { El hombre } \\
\text { de bien }\end{array}$ & $\begin{array}{l}\text { Lope } \\
\text { de Vega }\end{array}$ & $\begin{array}{l}\text { Teresa de } \\
\text { Guzmán }\end{array}$ & Madrid & [1736] & s.n. & $\begin{array}{l}\text { Lonja de } \\
\text { Comedias }\end{array}$ \\
\hline $\begin{array}{l}\text { El rey don } \\
\text { Alfonso, el } \\
\text { de la mano } \\
\text { horadada }\end{array}$ & $\begin{array}{l}\text { Luis Vélez } \\
\text { de Guevara } \\
\text { (atribuida) }\end{array}$ & $\begin{array}{l}\text { Teresa de } \\
\text { Guzmán }\end{array}$ & Madrid & [1736] & s.n. & $\begin{array}{l}\text { Lonja de } \\
\text { Comedias }\end{array}$ \\
\hline $\begin{array}{l}\text { Escarmientos } \\
\text { para el cuerdo }\end{array}$ & $\begin{array}{l}\text { Tirso } \\
\text { de Molina }\end{array}$ & $\begin{array}{l}\text { Teresa de } \\
\text { Guzmán }\end{array}$ & Madrid & [1736] & s.n. & $\begin{array}{l}\text { Lonja de } \\
\text { Comedias }\end{array}$ \\
\hline
\end{tabular}




\begin{tabular}{|c|c|c|c|c|c|c|}
\hline Título & Autor & Editor & Lugar & Fecha & Impresor & Librero \\
\hline $\begin{array}{l}\text { La elección } \\
\text { por la virtud }\end{array}$ & $\begin{array}{l}\text { Tirso } \\
\text { de Molina }\end{array}$ & $\begin{array}{l}\text { Teresa de } \\
\text { Guzmán }\end{array}$ & Madrid & [1736] & s.n. & $\begin{array}{l}\text { Lonja de } \\
\text { Comedias }\end{array}$ \\
\hline $\begin{array}{l}\text { La lealtad } \\
\text { contra la envidia }\end{array}$ & $\begin{array}{l}\text { Tirso } \\
\text { de Molina }\end{array}$ & $\begin{array}{l}\text { Teresa de } \\
\text { Guzmán }\end{array}$ & Madrid & [1736] & s.n. & $\begin{array}{l}\text { Lonja de } \\
\text { Comedias }\end{array}$ \\
\hline $\begin{array}{l}\text { La Peña } \\
\text { de Francia }\end{array}$ & $\begin{array}{l}\text { Tirso } \\
\text { de Molina }\end{array}$ & $\begin{array}{l}\text { Teresa de } \\
\text { Guzmán }\end{array}$ & Madrid & [1736] & s.n. & $\begin{array}{l}\text { Lonja de } \\
\text { Comedias }\end{array}$ \\
\hline $\begin{array}{l}\text { Segunda parte } \\
\text { de comedias } \\
\text { verdaderas }\end{array}$ & $\begin{array}{l}\text { Tirso } \\
\text { de Molina }\end{array}$ & $\begin{array}{l}\text { Teresa de } \\
\text { Guzmán }\end{array}$ & Madrid & [1736] & s.n. & $\begin{array}{l}\text { Lonja de } \\
\text { Comedias }\end{array}$ \\
\hline $\begin{array}{l}\text { Tercera parte } \\
\text { de comedias } \\
\text { verdaderas }\end{array}$ & $\begin{array}{l}\text { Tirso } \\
\text { de Molina }\end{array}$ & $\begin{array}{l}\text { Teresa de } \\
\text { Guzmán }\end{array}$ & Madrid & [1736] & s.n. & $\begin{array}{l}\text { Lonja de } \\
\text { Comedias }\end{array}$ \\
\hline $\begin{array}{l}\text { Todo es dar } \\
\text { en una cosa }\end{array}$ & $\begin{array}{l}\text { Tirso } \\
\text { de Molina }\end{array}$ & $\begin{array}{l}\text { Teresa de } \\
\text { Guzmán }\end{array}$ & Madrid & [1736] & s.n. & $\begin{array}{l}\text { Lonja de } \\
\text { Comedias }\end{array}$ \\
\hline $\begin{array}{l}\text { Amazonas } \\
\text { en las Indias }\end{array}$ & $\begin{array}{l}\text { Tirso } \\
\text { de Molina }\end{array}$ & $\begin{array}{l}\text { Teresa de } \\
\text { Guzmán }\end{array}$ & Madrid & [1736] & s.n. & $\begin{array}{l}\text { Lonja de } \\
\text { Comedias }\end{array}$ \\
\hline $\begin{array}{l}\text { La boba para } \\
\text { los otros y } \\
\text { discreta para sí }\end{array}$ & $\begin{array}{l}\text { Lope } \\
\text { de Vega }\end{array}$ & $\begin{array}{l}\text { Teresa de } \\
\text { Guzmán }\end{array}$ & Madrid & [1737] & s.n. & $\begin{array}{l}\text { Lonja de } \\
\text { Comedias }\end{array}$ \\
\hline $\begin{array}{l}\text { La reina Juana } \\
\text { de Nápoles }\end{array}$ & $\begin{array}{l}\text { Lope } \\
\text { de Vega }\end{array}$ & s.n. & Madrid & [1737] & s.n. & $\begin{array}{l}\text { Lonja de } \\
\text { Comedias }\end{array}$ \\
\hline $\begin{array}{l}\text { Servir con } \\
\text { mala estrella }\end{array}$ & $\begin{array}{l}\text { Lope } \\
\text { de Vega }\end{array}$ & s.n. & Madrid & [1737] & s.n. & $\begin{array}{l}\text { Lonja de } \\
\text { Comedias }\end{array}$ \\
\hline La dama boba & $\begin{array}{l}\text { Lope } \\
\text { de Vega }\end{array}$ & s.n. & Madrid & [1737] & s.n. & $\begin{array}{l}\text { Lonja de } \\
\text { Comedias }\end{array}$ \\
\hline $\begin{array}{l}\text { Los melindres } \\
\text { de Belisa }\end{array}$ & $\begin{array}{l}\text { Lope } \\
\text { de Vega }\end{array}$ & s.n. & Madrid & [1737] & s.n. & $\begin{array}{l}\text { Lonja de } \\
\text { Comedias }\end{array}$ \\
\hline
\end{tabular}

Tabla I. Sueltas y partes de comedias financiadas por Teresa de Guzmán entre 1733 y 1737

\begin{tabular}{|l|l|}
\hline Impresor/Imprenta & Ciudad \\
\hline Alonso y Padilla, Pedro José & Madrid \\
\hline Ariztia, Juan de & Madrid \\
\hline Campins, Pablo & Barcelona \\
\hline Colegio de Nuestra Señora de la Asunción & Córdoba \\
\hline Díaz, Pedro José Pablo & Sevilla \\
\hline Escuder, Pedro & Barcelona \\
\hline Espartosa, José de & Alcalá \\
\hline Fernández, Manuel & Madrid \\
\hline García de Infanzón, Juan, herederos de & Madrid \\
\hline García, Francisco Javier & Madrid \\
\hline González, José & Madrid \\
\hline
\end{tabular}




\begin{tabular}{|l|l|}
\hline Impresor/Imprenta & Ciudad \\
\hline Guasch, Ignacio & Barcelona \\
\hline Hierro, Francisco del, herederos de & Madrid \\
\hline Imprenta Real, Casa del Correo Viejo & Sevilla \\
\hline Juan Pérez, Casa de & Madrid \\
\hline Leefdael, Francisco de & Sevilla \\
\hline Leefdael, Francisco de, viuda de & Sevilla \\
\hline Marín, Antonio & Madrid \\
\hline Martínez Abad, José Francisco & Madrid \\
\hline Mora, Alfonso de & Madrid \\
\hline Navarro y Armijo, José & Sevilla \\
\hline Onorato, Francisco García de & Salamanca \\
\hline Orga, José de & Valencia \\
\hline Padrino, José & Sevilla \\
\hline Paz, imprenta de la calle de la & Madrid \\
\hline Peralta, Bernardo de & Córdoba \\
\hline Piferrer, Juan Francisco & Barcelona \\
\hline Plaza del Carbón, imprenta de la & Zaragoza \\
\hline Riego, Alonso del & Valladolid \\
\hline Sánchez, Joaquín & Madrid \\
\hline Santa Cruz, imprenta de la & Salamanca \\
\hline Santa Iglesia, imprenta de la & Burgos \\
\hline Sanz, Antonio & Madrid \\
\hline Sanz, Juan & Madrid \\
\hline Serra, Juan & Barcelona \\
\hline Surià y Burgada, Francisco & Barcelona \\
\hline Senant, Thomas & Cervera \\
\hline Universidad, imprenta de la & Sevilla \\
\hline Vallestilla, imprenta de la & Sevilla \\
\hline Villar y Monroy, Juan de, herederos de & Madrid \\
\hline Zúñiga, Juan de & inos \\
\hline
\end{tabular}

Tabla II. Impresores de la península Ibérica que publicaron ediciones teatrales entre 1700 y 1750 


\begin{tabular}{|c|c|c|c|c|c|}
\hline Autor & Título & Editor & Lugar & Fecha & Impresor \\
\hline $\begin{array}{l}\text { Tirso de } \\
\text { Molina }\end{array}$ & La república al revés & $\begin{array}{l}\text { Teresa de } \\
\text { Guzmán }\end{array}$ & Madrid & [1733] & S. n. \\
\hline $\begin{array}{l}\text { Tirso de } \\
\text { Molina }\end{array}$ & $\begin{array}{l}\text { El castigo del pensé } \\
\text { qué II }\end{array}$ & $\begin{array}{l}\text { Teresa de } \\
\text { Guzmán }\end{array}$ & Madrid & {$[1734]$} & s. n. \\
\hline $\begin{array}{l}\text { Hoz y Mota, } \\
\text { Juan de la }\end{array}$ & El castigo de la miseria & $\begin{array}{l}\text { Teresa de } \\
\text { Guzmán }\end{array}$ & Madrid & [1734] & S. n. \\
\hline $\begin{array}{l}\text { Tirso de } \\
\text { Molina }\end{array}$ & El vergonzoso en Palacio & $\begin{array}{l}\text { Teresa de } \\
\text { Guzmán }\end{array}$ & Madrid & [1734] & s. n. \\
\hline $\begin{array}{l}\text { Tirso de } \\
\text { Molina }\end{array}$ & El castigo del pensé qué I & $\begin{array}{l}\text { Teresa de } \\
\text { Guzmán }\end{array}$ & Madrid & [1734] & s. n. \\
\hline $\begin{array}{l}\text { Tirso de } \\
\text { Molina }\end{array}$ & Ventura te dé Dios, hijo & $\begin{array}{l}\text { Teresa de } \\
\text { Guzmán }\end{array}$ & Madrid & [1734] & s. n. \\
\hline $\begin{array}{l}\text { Tirso de } \\
\text { Molina }\end{array}$ & El amor y la amistad & $\begin{array}{l}\text { Teresa de } \\
\text { Guzmán }\end{array}$ & s.l. & {$[1734]$} & s. n. \\
\hline $\begin{array}{l}\text { Tirso de } \\
\text { Molina }\end{array}$ & Marta la piadosa & $\begin{array}{l}\text { Teresa de } \\
\text { Guzmán }\end{array}$ & Madrid & [1734] & s. n. \\
\hline $\begin{array}{l}\text { Ruiz de } \\
\text { Alarcón, } \\
\text { Juan }\end{array}$ & $\begin{array}{l}\text { Nunca poco costó } \\
\text { mucho y los pechos } \\
\text { privilegiados }\end{array}$ & $\begin{array}{l}\text { Teresa de } \\
\text { Guzmán }\end{array}$ & Madrid & [1735] & S. n. \\
\hline $\begin{array}{l}\text { Ruiz de } \\
\text { Alarcón, } \\
\text { Juan }\end{array}$ & La crueldad por el honor & $\begin{array}{l}\text { Teresa de } \\
\text { Guzmán }\end{array}$ & Madrid & [1735] & S. n. \\
\hline $\begin{array}{l}\text { Ruiz de } \\
\text { Alarcón, } \\
\text { Juan }\end{array}$ & $\begin{array}{l}\text { Lo que mucho vale } \\
\text { mucho cuesta en } \\
\text { ganar amigos }\end{array}$ & $\begin{array}{l}\text { Teresa de } \\
\text { Guzmán }\end{array}$ & Madrid & [1735] & s. n. \\
\hline $\begin{array}{l}\text { Ruiz de } \\
\text { Alarcón, } \\
\text { Juan }\end{array}$ & $\begin{array}{l}\text { Los empeños de un } \\
\text { engaño }\end{array}$ & $\begin{array}{l}\text { Teresa de } \\
\text { Guzmán }\end{array}$ & Madrid & [1735] & S. n. \\
\hline $\begin{array}{l}\text { Tirso de } \\
\text { Molina }\end{array}$ & Privar contra su gusto & $\begin{array}{l}\text { Teresa de } \\
\text { Guzmán }\end{array}$ & Madrid & {$[1735]$} & s. n. \\
\hline $\begin{array}{l}\text { Tirso de } \\
\text { Molina }\end{array}$ & $\begin{array}{l}\text { Favorecer a todos y } \\
\text { no amar a ninguna }\end{array}$ & $\begin{array}{l}\text { Teresa de } \\
\text { Guzmán }\end{array}$ & Madrid & [1735] & s. n. \\
\hline $\begin{array}{l}\text { Tirso de } \\
\text { Molina }\end{array}$ & $\begin{array}{l}\text { La mujer que manda } \\
\text { en casa }\end{array}$ & $\begin{array}{l}\text { Teresa de } \\
\text { Guzmán }\end{array}$ & Madrid & [1735] & S. n. \\
\hline $\begin{array}{l}\text { Ruiz de } \\
\text { Alarcón, } \\
\text { Juan }\end{array}$ & $\begin{array}{l}\text { La prueba de las } \\
\text { promesas }\end{array}$ & $\begin{array}{l}\text { Teresa de } \\
\text { Guzmán }\end{array}$ & Madrid & [1735] & s. n. \\
\hline $\begin{array}{l}\text { Tirso de } \\
\text { Molina }\end{array}$ & El pretendiente al revés & $\begin{array}{l}\text { Teresa de } \\
\text { Guzmán }\end{array}$ & Madrid & [1735] & S. n. \\
\hline $\begin{array}{l}\text { Tirso de } \\
\text { Molina }\end{array}$ & $\begin{array}{l}\text { Amar por razón de } \\
\text { estado }\end{array}$ & $\begin{array}{l}\text { Teresa de } \\
\text { Guzmán }\end{array}$ & Madrid & [1735] & s. n. \\
\hline $\begin{array}{l}\text { Lope de } \\
\text { Vega }\end{array}$ & La batalla del honor & $\begin{array}{l}\text { Teresa de } \\
\text { Guzmán }\end{array}$ & Madrid & [1735] & S. n. \\
\hline
\end{tabular}




\begin{tabular}{|l|l|l|l|l|l|}
\hline Autor & Título & Editor & Lugar & Fecha & Impresor \\
\hline $\begin{array}{l}\text { Lope de } \\
\text { Vega }\end{array}$ & La obediencia laureada & $\begin{array}{l}\text { Teresa de } \\
\text { Guzmán }\end{array}$ & Madrid & {$[1735]$} & s. n. \\
\hline $\begin{array}{l}\text { Lope de } \\
\text { Vega }\end{array}$ & El hombre de bien & $\begin{array}{l}\text { Teresa de } \\
\text { Guzmán }\end{array}$ & Madrid & [1736] & s. n. \\
\hline $\begin{array}{l}\text { Tirso de } \\
\text { Molina }\end{array}$ & La Peña de Francia & $\begin{array}{l}\text { Teresa de } \\
\text { Guzmán }\end{array}$ & Madrid & [1736] & s. n. \\
\hline
\end{tabular}

Tabla III. Grupo de sueltas financiadas por Teresa de Guzmán en las que se observa el uso del florón como recurso ornamental

\begin{tabular}{|l|l|l|}
\hline Impresor & Lugar & Fechas \\
\hline Alonso y Padilla, Pedro José & Madrid & $1716-1765$ \\
\hline Ariztia, Juan de & Madrid & $1712-1741$ \\
\hline García de Infanzón, Juan, herederos de & Madrid & $1730-1737$ \\
\hline González, José & Madrid & $1729-1763$ \\
\hline Hierro, Francisco del, herederos de & Madrid & $1728-1767$ \\
\hline Sanz, Antonio & Madrid & $1728-1770$ \\
\hline
\end{tabular}

Tabla IV. Impresores de la península Ibérica que emplean el florón en sus ediciones

\begin{tabular}{|l|l|l|l|}
\hline Impresor & Lugar & Fechas & Mm. \\
\hline Ariztia, Juan de & Madrid & $1712-1741$ & Filosofía: 75 \\
\hline González, José & Madrid & $1729-1763$ & Filosofía: 75 \\
\hline Sanz, Antonio & Madrid & $1728-1770$ & Filosofía: 75 \\
\hline
\end{tabular}

Tabla V. Tipos de letra de cada uno de los talleres seleccionados

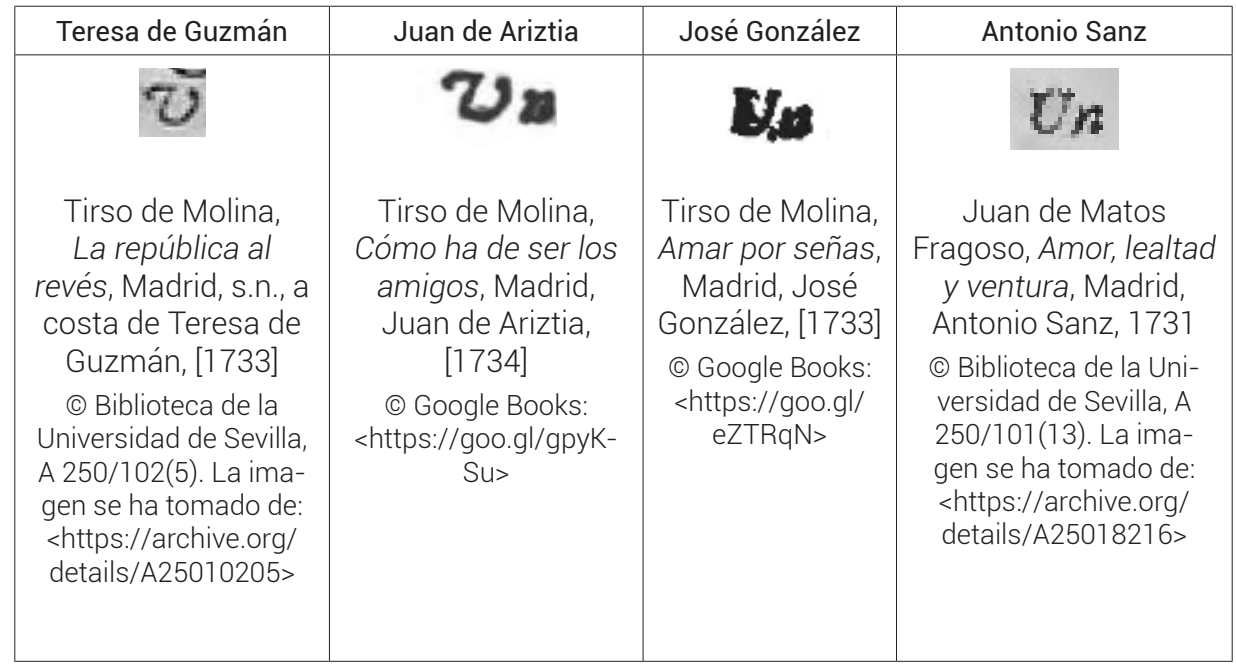

Tabla VI. Tipos de letra u cursiva 


\section{BiBLIOgRAFÍA}

Bainton, Cecilia, «Las comedias sueltas, ¿todavía un problema bibliográfico?», en El Libro antiguo español, ed. Pedro Cátedra García y María Luisa López-Vidriero, Salamanca, Ediciones de la Universidad de Salamanca, 1988, pp. 56-61.

Cardona, Ángeles, Cruickshank, Don, y Cunningham, Martin (eds.), Pedro Calderón de la Barca, La púrpura de la rosa, Kassel, Reichenberger, 1990.

Cruickshank, Don, «Introducción: Calderón y el comercio español del libro», en Bibliographisches Handbuch der Calderón-Forschung / Manual bibliográfico calderoniano, ed. Kurt y Roswitha Reichenberger, Teil III / Tomo III, Kassel, Verlag Thiele \& Schwarz, 1981, pp. 3-15.

Cruickshank, Don, «The Editing of Spanish Golden-Age Plays from Early Printed Versions», en Editing the comedia, ed. Michael Mcgaha y Frank P. Casa, Michigan, Michigan Romance Studies, 1985, pp. 52-103.

Cruickshank, Don, «Some Notes on the Printing of Plays in Seventeenth Century Seville», The Library, 6-11, 3, 1989, pp. 231-252.

Cruickshank, Don, «Some Problems Posed by suelta Editions of Plays», en Editing the comedia II, ed. Michael Mcgaha y Frank P. Casa, Michigan, Michigan Romance Studies, 1991, pp. 97-123.

Cruickshank, Don, «Sueltas», en Diccionario de la comedia del Siglo de Oro, ed. Frank P. Casa, Luciano García Lorenzo y Germán Vega García-Luengos, Madrid, Castalia, 2002, pp. 278-279.

Cruickshank, Don, «Towards an Atlas of Italic Types Used in Spain, 1528-1700», Bulletin of Spanish Studies, 81, 7-8, 2004, pp. 973-1010.

Cruickshank, Don, y Varey, John E. (eds.), Pedro Calderón de la Barca, Comedias, London, Gregg International / Tamesis, 1973.

Cruickshank, Don, y Wilson, Edward M., «A Calderón's Collection in Dr Steeven's Hospital», Long Room, 9, 1974, pp. 17-27.

Fernández Valladares, Mercedes, «Biblioiconografía y literatura popular impresa: la ilustración de los pliegos sueltos burgaleses (o de babuines y estampas celestinescas)», eHumanista, 21, 2012, pp. 87-131.

Gómez Sánchez-Ferrer, Guillermo, Del corral al papel. Estudio de impresores españoles de teatro en el siglo XVII, Tesis doctoral, Madrid, Universidad Complutense de Madrid, 2015.

Moll, Jaime, «Las nueve partes de Calderón editadas en comedias sueltas (Barcelona 1763-1767)», Boletín de la Real Academia Española, 51, 1971, pp. 259-304.

Moll, Jaime, «Diez años sin licencias para imprimir comedias y novelas en los reinos de Castilla: 1625-1634», Boletín de la Real Academia Española, 54, 1974, pp. 97-103. 
Reichenberger, Kurt, «El "Jardín ameno". Primeros pasos hacia la reconstrucción de una colección de comedias de finales del siglo XVII hasta comienzos del siglo XVIII», Diálogos hispánicos de Ámsterdam, 8.2, 1989, pp. 287-300.

Szmuk, Szilvia E., «A Prelude to a Union List of Comedias Sueltas», en Silva. Studia philologica in honorem Isaías Lerner, ed. Isabel Lozano Renieblas y Juan Carlos Mercado, Madrid, Castalia, 2001, pp. 675-686.

Ulla Lorenzo, Alejandra, «Teresa de Guzmán (1733-1737), "viuda y mercadera de libros" de comedias», Hispanófila, 178, 2016, pp. 233-249.

Ulla Lorenzo, Alejandra, «Nuevos datos sobre la Lonja de Comedias de la Puerta del Sol (1733-1786)», Neophilologus, 102.4, 2018, pp. 483-495.

Vega García-Luengos, Germán, «La investigación sobre los formatos del teatro español del siglo XVII en la imprenta», Bibliologia, 4, 1999, pp. 21-45.

Wilson, Edward M., «Comedias sueltas - a Bibliographical Problem», en The comedias of Calderón, Comedias, vol. I, ed. Don Cruickshank y John E. Varey, The textual criticism of Calderón's comedias, ed. Don Cruickshank, London, Gregg International / Tamesis, 1973, pp. 211-219.

Wilson, Edward, y Cruickshank, Don, Samuel Pepy's Spanish Plays, London, The Bibliographical Society, 1980. 